\title{
An Examination of Pre-service Teachers’ Attributions for Students with Specific Learning Difficulties
}

\begin{abstract}
One of the most important factors in the successful inclusion of students with specific learning difficulties in mainstream classrooms is the teacher. Despite strong support for inclusion, mainstream teachers still demonstrate mixed responses to the inclusion of certain students in the classrooms. Further, their attitudes toward inclusion seem to be formed during their initial training. The purpose of this research was to examine the attitudes of pre-service teachers towards students with specific learning difficulties by analysing their attributional responses to hypothetical students. Participants included 205 pre-service teachers, and the results demonstrated that the pre-service teachers' attributional responses differed according to whether or not the hypothetical students had a specific learning difficulty. Their attributional responses were likely to have an unintended negative impact on students’ attributions, self-efficacy and motivation. One implication of these findings is that pre-service teacher training needs to include a focus on teachers' attitudes and behaviours in inclusive classrooms.
\end{abstract}

\section{Key words:}

specific learning difficulties; attribution theory; pre-service teachers; inclusive classrooms. 


\section{Introduction}

The principle of inclusive education is now well-established, due in large part to its promotion in global campaigns such as the World Declaration on Education for All (UNESCO, 1990), the Salamanca statement (UNESCO, 1994), and the policy guidelines on inclusion in education (UNESCO, 2007). Inclusive education embraces different populations of children, but has most commonly been interpreted as the education of children with disabilities in mainstream schools. Western countries, including the United Kingdom, have enshrined the inclusion of students within legislation, a trend that has gained momentum globally. Several authors have argued that teachers need knowledge of inclusive principles and practices along with positive attitudes for the successful inclusion of students with disabilities (Carroll, Forlin, \& Jobling, 2003; Forlin, 2010). Given the relationships among the knowledge, skills, and attitudes of teachers, and the likelihood that teachers' practices are shaped by their attitudes — which may differ according to the type of special educational need — we were interested in understanding teachers' attitudes to students with specific learning difficulties. Further, we wanted to investigate the attitudes of pre-service teachers, who had undertaken a unit on inclusive education, from the perspective of attribution theory.

\section{Inclusion}

While legislation and policies are critical prerequisites, research has consistently demonstrated that teachers are the key to successful inclusion (Avramidis \& Norwich, 2002; de Boer, Pijl, \& Minnaert, 2011; Sharma, Forlin, \& Loreman, 2008; Stronge, Ward, \& Grant, 2011). Teachers' knowledge, beliefs and attitudes have all been examined as potential factors influencing the implementation of inclusive educational practices. Researchers have argued that teachers need both theoretical and practical knowledge (Mittler, 1992), which has been reflected in the content of programs developed for pre-service teachers. However, knowledge 
and skills cannot be easily separated from teacher attitudes, which also need to form part of teacher training (Avramidis, Bayliss, \& Burden, 2000; Carroll, et al., 2003; Forlin, 2010). Indeed, some authors (e.g., Kozleski \& Waitoller, 2010) critique the traditional focus on knowledge and technical skills in teacher training, and argue instead for a focus on selfreflection. While there is some debate as to the relative importance of attitudes, knowledge and skills for teachers in inclusive classrooms, the current research focuses on the attitudes of pre-service teachers who have had minimal exposure in their training to inclusive education.

Despite some evidence that teachers support inclusion in principle (de Boer, et al., 2011), the research regarding teacher acceptance of inclusion is far from being unequivocal. Some researchers reported positive attitudes on the part of teachers to the principle of the inclusion of students with disabilities (Abbott, 2006; Avramidis \& Kalyva, 2007; Marshall, Ralph, \& Palmer, 2002). Demonstrating the gap between principles and practice, however, other research has reported neutral or ambivalent attitudes and limited knowledge on the part of mainstream teachers (Engelbrecht, 2006; Ring, 2005; Walton, 2011). In a review of 26 empirical studies focused on teachers in mainstream primary schools, for example, de Boer and her colleagues reported that most teachers were neutral or negative in their attitudes towards inclusive education (de Boer, et al., 2011).

Research has demonstrated that attitudes to inclusion are more positive among teachers who have contact with individuals with disabilities (Parasuram, 2006), although these results are found more consistently when the teacher has greater experience with inclusion (Avramidis \& Kalyva, 2007; Batsiou, Bebetsos, Panteli, \& Antoniou, 2008; Brady \& Woolfson, 2008; Malinen, Savolainen, Engelbrecht, Xu, Nel, Nel, \& Tlale, 2013). Other research, however, has failed to find the same pattern (e.g., Woolfson \& Brady, 2009). The conflicting results 
may be partially explained, according to Woolfson and Brady (2009), on whether teachers felt they had been successful in their previous classroom encounters with students having special educational needs. Further, research has consistently demonstrated that beginning teachers are more positive in their attitudes to inclusive education than are their more experienced counterparts (Alghazo \& Naggar Gaad, 2004; Glaubman \& Lifshitz, 2001). One possible explanation of this is that many pre-service teacher-training institutions now include some coursework on inclusive education, which more experienced teachers may not have received (Brady \& Woolfson, 2008).

Research has generally demonstrated a link between teacher attitudes and training in inclusive practices (Avramidis \& Norwich, 2002; Batsiou, et al., 2008; Loreman, Forlin, \& Sharma, 2007). In particular, long-term training has been associated with teachers demonstrating more positive attitudes (Avramidis \& Kalyva, 2007). The research has demonstrated, for example, that teachers who have undertaken higher qualifications demonstrate more positive attitudes when compared to those with lower educational qualifications (Sharma, Ee, \& Desai, 2003). Nevertheless, there are some studies that have not supported this positive relationship between training and teacher attitudes (Brady \& Woolfson, 2008; Romi \& Leyser, 2006).

Teacher attitudes have been found to vary according to the type of disability, with mild disabilities more readily accepted by teachers than more severe disabilities (Lifshitz, Glaubman, \& Issawi, 2004; Lindsay, 2007), and emotional and behavioural issues more negatively received than physical or intellectual disabilities (Alghazo \& Naggar Gaad, 2004; Avramidis, et al., 2000; Glaubman \& Lifshitz, 2001). Specific learning difficulties have also been reported as causing teachers most concern (Cook, 2001; Glaubman \& Lifshitz, 2001). 
There has been increasing interest recently on the relationship of teacher self-efficacy to teacher attitudes wherein teachers with higher self-efficacy held more positive attitudes toward inclusion (Leyser, Zeiger, \& Romi, 2011; Malinen, et al., 2013; Malinen, Savolainen, \& Xu, 2012; Woolfolk Hoy \& Spero, 2005; Woolfson \& Brady, 2009). Of particular interest to our current research has been work that demonstrates the connection between teacher selfefficacy and the attributions that teachers make for students with special educational needs (Brady \& Woolfson, 2008; Jordan, Glenn, \& McRichmond, 2010; Woolfson \& Brady, 2009). Given this relationship between teacher self-efficacy and attributional style among in-service teachers, we were interested in the attributions that pre-service teachers made for students with specific learning difficulties. Pre-service teachers are of interest because of their more favorable attitudes towards inclusive education (Alghazo \& Naggar Gaad, 2004; Garmon, 2004) and because research has consistently demonstrated that teachers’ self-efficacy beliefs — and, hence, their attributional styles — are formed early and are resilient against change in their subsequent careers (Berry, 2008; Ross \& Bruce, 2007). For the purpose of this study, then, pre-service teachers' attitudes toward students with SLD are examined through the attributions they make.

\section{Attribution Theory}

Attribution theory provides the foundation for the current research examining pre-service teachers' attitudes to children with specific learning difficulties. Attributions refer to the conclusions drawn by individuals to explain why a behavior or event occurred (Weiner, 1986). According to Weiner $(1979,1985)$, academic performance may variously be attributed to the broad categories of ability, effort, task difficulty and luck. 
Weiner argued that causal attributions could be organized into three dimensions: locus of causality, stability and controllability. Locus of causality indicates the source of the attribution as either internal or external to the individual. For example, a student who attributes an academic success to ability or personal effort is illustrative of internal locus of causality, while a student who attributes that success to chance factors is illustrative of external locus of causality. Stability indicates that the cause is persistent over time, such as when a student attributes academic success to ability. By contrast, the amount of effort the student expends is variable and, therefore, unstable. Controllability indicates the extent to which an individual is able to control the cause. To illustrate, students can determine the amount of effort they will exert on a task (controllable) but cannot so readily influence the difficulty level of the task (uncontrollable).

The attributions that students make with regard to these three dimensions influence their academic and emotional outcomes. Further, the attributions that teachers make about their students’ performance will be reflected in their behaviors towards their students and, ultimately, may influence the students’ outcomes (Weiner, 1979, 1986; Weiner, Russell, \& Lerman, 1978). To illustrate, if a teacher attributes a student's failure to internal factors within the child, that teacher is less likely to modify instruction to assist the student (Jordan, et al., 2010). The student, in turn, may feel guilt or shame and develop a lower self-esteem as a consequence (Weiner 1979, 1986). The stability dimension influences the students' future expectations regarding performance such that when a teacher attributes failure to a stable factor, the student may not persist with classroom tasks (Weiner 1979, 1986). Finally, the controllability dimension suggests that there can be unintended consequences for students if teachers' attributions communicate that their performance is outside their control. For example, if a teacher shows sympathy towards students after they fail a task, the students 
could perceive that the teacher believes they do not have the ability to succeed, thereby lowering the students' beliefs about themselves and their future performance (Clark, 1997). By contrast, if the teacher displays frustration or anger following students' failure, the students retain control (Clark \& Artiles, 2000). The teachers’ attributions, then, may influence the students’ future motivation and learning strategies (Reyna \& Weiner, 2001). Thus, while teachers may have the best intentions in offering students with disabilities sympathetic assistance or unwarranted praise for success on easy tasks, students may infer they have low ability and can expect future failure (Author et al., 2010; Author et al., 2011; Schunk, Pintrich, \& Meece, 2008).

\section{Attributions for Students with Specific Learning Difficulties}

Students with specific learning difficulties (SLD) form the largest group of students with special educational needs in inclusive classrooms (Lerner \& Johns, 2009). Clark (1997) argued that teachers' attributions for students with SLD were likely to be internal, stable, and uncontrollable. For example, students with SLD were treated more sympathetically following failure than were their peers without SLD, and teachers generally expected the students with SLD to fail on future school tasks (Clark, 1997). Clark’s research has been supported by research elsewhere (Author et al., 2010; Author et al., 2011; Georgiou, Christou, Stavrinides, \& Panoura, 2002), which demonstrates that teachers’ attributions can convey to students with SLD that they are less able and can expect lower academic outcomes than their peers.

While most students hold a ‘positive attribution style’ (Jacobson, Lowery, \& DuCette, 1986), which means that they are likely to attribute their successes to internal, controllable causes and failures to external causes, the reverse is true for students with SLD. These students' negative attribution style is evident in their attributing success to external factors such as 
luck, and failure to their low ability (Waheeda \& Grainger, 2002). The research has demonstrated that the attributional styles of students with SLD, compared to mainstream peers, are generally reflected in lower levels of self-esteem, persistence, motivation, and expectation of future academic success (Gans, Kenny, \& Ghany, 2003; Nunez, GonzalezPienda, Gonzalez-Pumariega, Roces, Alvarez, Gonzalez, Cabanach, Valle, \& Rodriguez, 2005; Stone \& May, 2002). The negative impact for academic success inherent in the documented attributional styles of students with SLD (Heiman, 2006) underscores the critical role that teachers play in reversing such cycles. It is important, therefore, that we understand the attributions made by mainstream teachers regarding students with SLD in their classrooms.

\section{The British Context}

British educational jurisdictions must respond to the needs of students with SLD who represent a significant proportion of students requiring special accommodations in inclusive classrooms. Educational policy is the responsibility of the Department for Education (DfE), and Local Education Authorities (LEAs), which means that there can be variation across the country with respect to definition, identification, and curricular adaptations for SLD.

Nationally, however, the Special Educational Needs Code of Practice (DfES, 2001) policy in England, acknowledges that students’ needs are diverse and often interrelated:

This guidance does not assume that there are hard and fast categories of special educational need. It recognizes...that each child is unique .... LEAs should recognize that there is a wide spectrum of special educational needs that are frequently interrelated, although there are also specific needs that usually relate directly to particular types of impairment. (DfES, 2001, p. 85) 
SLD is explicitly delineated as "children and young people with speech and language delay, impairments or disorders, specific learning difficulties, such as dyslexia and dyspraxia, hearing impairment and those who demonstrate features within the autistic spectrum” (DfES, 2001, p. 86).

In the UK, therefore, SLD is recognized independently, and the Special Educational Needs Code of Practice (DfES, 2001) states that LEAs should implement programs in collaboration with schools and, where relevant, external support services. Currently there are no mandatory minimum requirements for teacher training courses to provide content on students with SLD. An independent report for the Government (The Rose Review) stated that SLD should be included in pre-service teacher training courses (Rose, 2009). However, the DfE's new Teachers' Standards (DfE, 2012) still did not ensure that teachers are equipped to cater for students with SLD. Thus, many British teachers may be ill-prepared to meet the academic and social needs of students with SLD, when they commence their teaching careers.

\section{Summary}

Research has established that the teacher is one critical element in the successful inclusion of students with disabilities in mainstream classrooms. Given the conflicting evidence regarding how well students with SLD are accepted by teachers in inclusive settings (Jordan, et al., 2010), we focused on this group for the current study. The research on teacher attitudes towards the inclusion of students with SLD has been extensive, but there has been less focus on teachers' attributional styles in relation to students with SLD. Further, there has been scant attention to the attributions that pre-service teachers make for students with SLD. We therefore aimed to build on prior research by examining British pre-service primary-junior school teachers’ attributions for students with SLD. 


\section{Method}

The research explored to what extent pre-service teachers' knowledge of the presence or absence of a SLD would influence (a) the feedback given to a number of hypothetical boys based on their ability and the effort they expended, (b) the frustration and sympathy felt towards each of the boys, and (c) the expectations held for each student's future. 


\section{Site and Participants}

Pre-service teachers were drawn from two universities in the United Kingdom and were enrolled in a one-year postgraduate certificate of education (PGCE), which followed the completion of an initial undergraduate degree. The participants were 205 pre-service teachers enrolled in the PGCE course. The sample was $87 \%$ female and $13 \%$ male, which is similar to the ratio of primary teachers in the United Kingdom (General Teaching Council for England, 2009). Furthermore, 70\% were aged 21-25, $22.5 \%$ were $26-35$, and $7.5 \%$ were 36 and over.

\section{Context}

The PGCE primary course at the two universities prepares pre-service teachers to teach primary and junior age students (5-11). The course is 39 weeks long and includes $18-20$ weeks of practical experience in schools. The PGCE course is taught by university lecturers and teachers in partnership local primary schools. The course consists of a number of subjects to meet the requirements of the Training and Development Agency for Schools (TDA). Professional Standards for Qualified Teacher Status (QTS) include professional studies (covering inclusion, classroom management, and planning and programming), core curriculum studies (English, Mathematics, and Science) as well as foundation curriculum studies (e.g., History, Physical Education, Information and Communications Technology, etc). All students complete a foundation subject on 'Inclusive Education', which introduces them to the broad tenets of inclusive education and students with special educational needs. The aims of the foundation subject were to contextualise the meaning of inclusion; develop an understanding of current research on the specific types of disabilities; increase understanding and enhance practice of the approaches to teaching specific types of disabilities and learning needs; and, increase awareness of the historical context of disability. Our participants had completed their 18-20 weeks of practical experience within inclusive classroom settings and were close to completing their teacher training. 


\section{Instrument}

The survey instrument was adapted from Clark's (1997) research, which examined the way in which American primary school teachers perceived the achievements of students with and without SLD. Eight vignettes described hypothetical boys who had taken a classroom test and failed. We retained the instrument's use of boys in order to eliminate the potential confounding variable of the child's gender on the participants' attributions. The vignettes did not identify the cause of the boys' failures in order to stimulate causal explanations by the participants. The description of each vignette provided three types of information: a statement of student ability, the effort expended by the student, and academic performance. The descriptions identified half the boys as SLD and half as non-SLD (NLD), half as high ability and half as low ability, and, half as expending high effort and half as expending low effort, but specific terms were not used. The boys were matched on ability (high/low), on typical effort (high/low), and the presence/absence of a SLD (SLD/NLD). Finally, a matrix of 2 (ability) by 2 (effort) by 2 (SLD/NLD) was formed. An example of a vignette is:

Steven is a student in your class. He is of higher ability than many in the class but has difficulty with tasks he must do in writing, such as writing stories where he must formulate correct sentences and spell correctly. He receives support services which are helping him develop strategies to improve his written work. He works hard but slowly in class, using the methods he was taught and usually completes assignments. His homework is generally done properly.

After respondents read the vignettes, they were presented with four questions: (a) what feedback they would give to the child (very positive $(+5)-(-5)$ very negative), (b) the degree 
of frustration that they would feel towards the child (very little (0) - (6) very much), (c) the degree of sympathy that they would feel towards the child (very little (0) - (6) very much), and, (d) their expectation of the likelihood of the boy's future failure (very unlikely (0) - (6) very likely). Each of the four questions utilized a Likert scale response (for further detail regarding the vignettes, see Author et al., 2011). All the vignettes were presented in the survey randomly to avoid order effects.

There is a limitation in using vignette scenarios whereby participants may select different responses in the survey than they would in natural settings (Woolfson \& Brady, 2009). Furthermore, the reliance on self-report data is queried by some researchers due to factors around social desirability and reliability (Cook \& Campbell, 1979). However, others (Chan, 2009; Clunies-Ross, Little, \& Kienhuis, 2008) have contended that self-report data can be validated in similar ways to observational data, and may be less problematic in studies such as this one than in experimental studies.

The instrument was pilot tested by Clark (1997) to refine and validate the vignettes. Prior to pilot testing the vignettes, Clark worked with attribution researchers in developing the vignettes to validate the ability and effort levels exhibited by each student and identify which of the students had a learning disability. Clark (1997) then piloted it in two schools where participants completed the instrument and commented on the clarity of the vignettes. Following this the participants were asked to identify what types of students were in the vignettes. All participants perceived the four students who were served by the support program as having a learning disability. The authors in this study refined Clark's instrument and validated it in two phases. The vignettes were reviewed by Australian academics from the field of special education. Secondly, a pilot study of 36 pre-service teachers was conducted and participants were asked to comment on the clarity of the vignettes and 
questions. Minor revisions were made to the instrument in response to the pilot participants' comments.

\section{Procedure}

Following approval from the Human Research Ethics Committee of one participating university, the participants were surveyed in a lecture at the end of the final semester of their course. Participants were given an information sheet outlining the aims of the survey and informed that their participation was voluntary.

\section{Results}

A two (N/SLD) by two (ability) by two (effort) multivariate analysis of variance with repeated measures was conducted for the four dependent measures (feedback, frustration, sympathy, and expectation of future failure). Multivariate analysis of variance with repeated measures was used because the same measures can be collected multiple times for each subject but under different conditions. Each section reports the results of the repeated measures analysis by discussing the main effects for each variable (SLD status, ability level, and effort) and combined two and three-way interactions. The reported effect sizes utilize Cohen's small, medium, and large effect sizes where $\eta_{\mathrm{p}}{ }^{2}$ sizes are equal to $0.10,0.25$, and 0.40 respectively (cited in Richardson, 2011). Demographic data of participants were not examined.

Overall, significant main effects, from the multivariate analysis of variance repeated measures, for SLD status, $\mathrm{F}(1,205)=32.025, \mathrm{p}<.001, \eta_{\mathrm{p}}{ }^{2}=.389$; ability, $\mathrm{F}(1,205)=$ 63.182, $\mathrm{p}<.001, \eta_{\mathrm{p}}{ }^{2}=.557$; and, effort, $\mathrm{F}(1,205)=278.061, \mathrm{p}<.001, \eta_{\mathrm{p}}{ }^{2}=.847$, were found 
for attributional response. In particular, a two-way interaction between SLD and ability was significant and produced a small main effect, $F(1,205)=6.403, \mathrm{p}<.001, \eta_{\mathrm{p}}{ }^{2}=.113$. However, SLD status and effort produced a large interaction effect, $F(1,205)=36.508, \mathrm{p}<$ $.001, \eta_{\mathrm{p}}{ }^{2}=.421$. A three-way interaction of SLD, ability and effort was significant and produced a medium main effect, $\mathrm{F}(1,205)=14.876, \mathrm{p}<.001, \eta_{\mathrm{p}}{ }^{2}=.228$. The following sections report the univariate analysis of variance using repeated measures for each individual attributional response.

\section{Feedback}

Table 1

Teachers’ Significant Feedback Means

\begin{tabular}{|c|c|c|c|c|c|c|c|c|}
\hline \multirow[b]{3}{*}{ LD Status } & \multicolumn{2}{|c|}{ LD } & \multicolumn{2}{|c|}{ NLD } & & & & \\
\hline & M & SD & M & SD & & & & \\
\hline & 3.085 & 1.08 & 2.896 & .105 & & & & \\
\hline & \multicolumn{2}{|c|}{ Low } & \multicolumn{2}{|c|}{ High } & & & & \\
\hline & $M$ & $S D$ & $M$ & $S D$ & & & & \\
\hline \multirow[t]{3}{*}{ Effort } & 2.213 & 1.40 & 3.768 & .90 & & & & \\
\hline & \multicolumn{2}{|c|}{ LD LE } & \multicolumn{2}{|c|}{ LD HE } & \multicolumn{2}{|c|}{ NLD LE } & $\overline{\mathrm{NLI}}$ & \\
\hline & M & SD & M & $\mathrm{SD}$ & M & $\mathrm{SD}$ & M & SD \\
\hline LD*Effort & 2.476 & 1.44 & 3.695 & .94 & 1.951 & 1.45 & 3.841 & 1.08 \\
\hline
\end{tabular}

A significant small size main effect for SLD status, $\mathrm{F}(1,205)=15.547, \mathrm{p}<.001, \eta_{\mathrm{p}}{ }^{2}=.071$, was found for feedback (Table 2). As Tables 1 and 2 show, this is in the $\eta_{\mathrm{p}}{ }^{2}$ and mean score differences between feedback given to the students with $(M=3.085)$ and without SLD $(M=$ 2.896), with greater positive feedback given to the students with SLD. There was no significant main effect for ability ( $\mathrm{p}>$.05) when considering feedback. Finally, a large significant main effect for effort, $F(1,205)=241.984, p<.001, \eta_{p}{ }^{2}=.543$, was found for feedback. The level of effort expended was the most highly significant main effect found for 
feedback. This can be seen in the $\eta_{\mathrm{p}}{ }^{2}$ and mean feedback scores given to the low effort $(\mathrm{M}=$ 2.213) and high effort students $(M=3.768)$ respectively.

Table 2

Teachers’ Significant Feedback Main Effects

\begin{tabular}{lccc}
\hline \multicolumn{1}{c}{ Effect } & F & $\eta^{2}$ & $p$ \\
& & & \\
\hline LD Status & 15.547 & .071 & .000 \\
Effort & 241.984 & .543 & .000 \\
LD ${ }^{\mathrm{x}}$ Effort & 49.968 & .197 & .000 \\
\hline
\end{tabular}

The responses of the pre-service teachers revealed a two-way interaction between a boy's level of effort and his SLD status $F(1,205)=49.968, \mathrm{p}<.001, \eta_{\mathrm{p}}{ }^{2}=.197$, when giving feedback (small-medium effect size). SLD status was particularly influential for the students who expend low effort. Finally, there was no significant three-way interaction effect between SLD, ability, and effort in regards to feedback. Thus feedback for test failure was governed by the amount of effort the students expend, with pre-service teachers' knowledge of a child's SLD status having a mediating influence on the feedback given.

\section{Frustration}

Table 3

Teachers' Significant Frustration Means

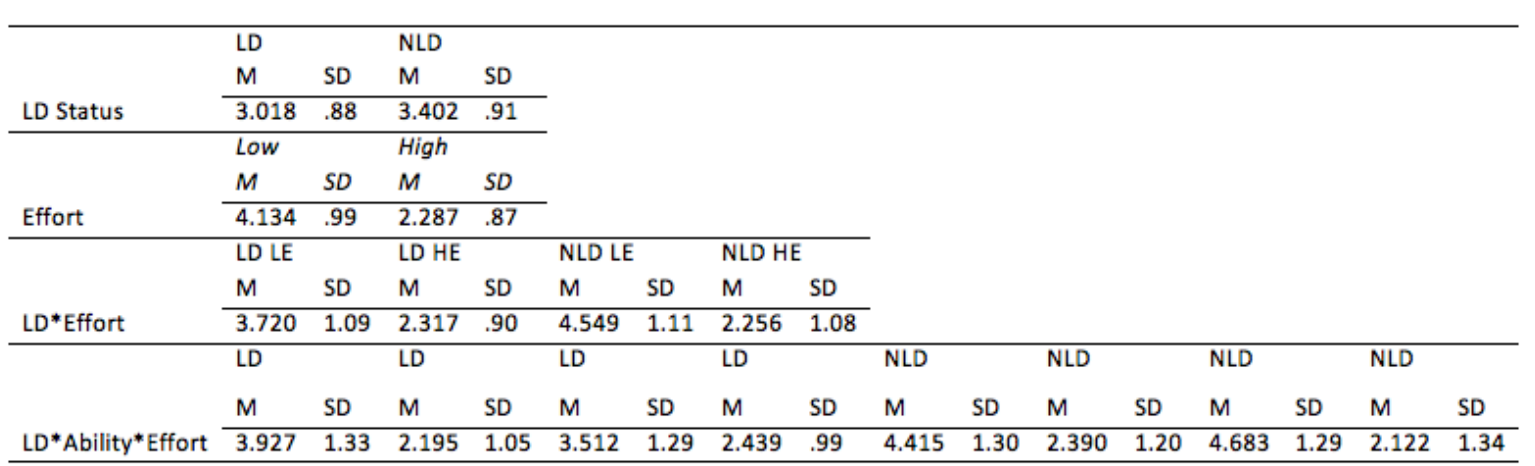


As illustrated in Tables 3 and 4, a significant (medium) main effect for SLD status, F(1, 205) $=67.126, \mathrm{p}<.001, \eta_{\mathrm{p}}{ }^{2}=.248$, was found for pre-service teacher frustration. The $\eta_{\mathrm{p}}{ }^{2}$ and mean score difference between frustration felt towards the students with $(M=3.018)$ and without SLD $(M=3.402)$ is indicative of this finding. However, there were no significant main effects for ability ( $\mathrm{p}>.05)$, indicating no differences in pre-service teachers’ frustrations towards high or low ability level students. Moreover, a large significant main effect found for frustration was effort, $F(1,205)=892.624, \mathrm{p}<.001, \eta_{\mathrm{p}}{ }^{2}=.814$. This can be noticed in the $\eta_{\mathrm{p}}{ }^{2}$ and mean scores of frustration felt towards the low effort $(\mathrm{M}=4.134)$ and high effort students $(M=2.287)$ respectively.

Table 4

Teachers' Significant Frustration Main Effects

\begin{tabular}{llll}
\hline Effect & F & $\eta^{2}$ & $p$ \\
\hline LD Status & 67.126 & .248 & .000 \\
Effort & 892.624 & .814 & .000 \\
LD ${ }^{\mathrm{x}}$ Effort & 83.637 & .291 & .000 \\
LD $^{\mathrm{x}}$ Ability & & & \\
& & & \\
\end{tabular}

The responses reflected a two-way interaction between a boy's level of effort and his SLD status with a moderate significant effect, $F(1,205)=83.637, \mathrm{p}<.01, \eta_{\mathrm{p}}{ }^{2}=.291$, in relation to feelings of frustration. Thus, SLD status was particularly influential for those who expended low amounts of effort with regards to levels of pre-service teachers’ frustration.

Additionally, effort was more influential in pre-service teachers' frustration level for the students without SLD than for students with SLD. Finally, there was a small significant threeway interaction effect among SLD, ability, and effort, $F(1,205)=26.880, \mathrm{p}<.01, \eta_{\mathrm{p}}{ }^{2}=.116$. 
Thus, the frustration felt towards students was governed by the level of effort expended and pre-service teachers' knowledge of a child's SLD status.

\section{Sympathy}

\begin{tabular}{|c|c|c|c|c|c|c|c|c|c|c|c|c|c|c|c|c|}
\hline \multicolumn{17}{|c|}{ Teachers' Significant Sympathy Mean } \\
\hline & LD & & NLD & & & & & & & & & & & & & \\
\hline & M & SD & M & SD & & & & & & & & & & & & \\
\hline \multirow[t]{3}{*}{ LD Status } & 4.378 & .83 & 4.213 & .87 & & & & & & & & & & & & \\
\hline & Low & & High & & & & & & & & & & & & & \\
\hline & M & SD & M & SD & & & & & & & & & & & & \\
\hline \multirow[t]{3}{*}{ Ability } & 4.409 & .90 & 4.183 & .83 & & & & & & & & & & & & \\
\hline & Low & & High & & & & & & & & & & & & & \\
\hline & M & SD & M & $S D$ & & & & & & & & & & & & \\
\hline \multirow[t]{3}{*}{ Effort } & 3.744 & .95 & 4.848 & .95 & & & & & & & & & & & & \\
\hline & LD LE & & LD HE & & NLD LE & & NLD HE & & & & & & & & & \\
\hline & M & SD & M & SD & M & SD & M & SD & & & & & & & & \\
\hline \multirow[t]{3}{*}{ LD*Effort } & 4.000 & 1.05 & 4.756 & .98 & 3.488 & 1.11 & 4.939 & 1.08 & & & & & & & & \\
\hline & LD & & LD & & LD & & LD & & NLD & & NLD & & NLD & & NLD & \\
\hline & M & SD & M & SD & M & SD & M & SD & M & SD & M & SD & M & SD & M & SD \\
\hline LD*Ability*Effort & 4.073 & 1.15 & 5.000 & 1.19 & 3.927 & 1.27 & 4.512 & 1.19 & 3.634 & 1.33 & 4.927 & 1.36 & 3.341 & 1.18 & 4.951 & 1.30 \\
\hline
\end{tabular}

A significant small main effect for SLD status, $F(1,205)=14.324, p<.001, \eta_{p}{ }^{2}=.066$, was found for sympathy (see Tables 5 and 6), with mean differences in pre-service teacher sympathy towards the students with $(M=4.378)$ and without SLD $(M=4.213)$. A significant small effect for ability, $\mathrm{F}(1,205)=23.849, \mathrm{p}<.001, \eta_{\mathrm{p}}{ }^{2}=.105$, was also found for sympathy. This can be seen in the $\eta_{\mathrm{p}}{ }^{2}$ and mean differences in pre-service teacher sympathy towards low ability $(M=4.409)$ and high ability students $(M=4.183)$. A significant main effect for effort, $\mathrm{F}(1,205)=221.490, \mathrm{p}<.001, \eta_{\mathrm{p}}{ }^{2}=.521$ (large effect size), was found for sympathy. The significance is noticeable with the $\eta_{\mathrm{p}}{ }^{2}$ and mean score differences between students who expend low effort $(M=3.744)$ and high effort $(M=4.848)$ respectively. 
Table 6

Teachers' Significant Sympathy Main Effects

\begin{tabular}{llll}
\hline Effect & $\mathrm{F}$ & $\eta^{2}$ & $p$ \\
\hline LD Status & 14.324 & .066 & .000 \\
Ability & 23.849 & .105 & .000 \\
Effort & 221.490 & .521 & .000 \\
LD ${ }^{\mathrm{x} E f f o r t}$ & 46.486 & .186 & .000 \\
LD*Ability*Effort & 10.885 & .051 & .000 \\
\hline
\end{tabular}

The responses demonstrated a two-way interaction between a student's SLD status and amount of effort expended when eliciting sympathy, $F(1,205)=46.486, \mathrm{p}<.001, \eta_{\mathrm{p}}{ }^{2}=.186$ (small-medium effect size). Finally, there was a small significant three-way interaction effect among SLD, ability, and effort in regards to sympathy, $\mathrm{F}(1,205)=10.885, \mathrm{p}<.01, \eta_{\mathrm{p}}{ }^{2}=$ .051 .

\section{Expectancy of Future Failure}

\begin{tabular}{|c|c|c|c|c|c|c|c|c|c|c|c|c|c|c|c|c|}
\hline hers Expecta & \multirow{2}{*}{\multicolumn{2}{|c|}{ LD }} & \multirow{2}{*}{\multicolumn{2}{|c|}{ NLD }} & & & & & & & & & & & & \\
\hline \multirow[b]{3}{*}{ LD Status } & & & & & & & & & & & & & & & & \\
\hline & $\mathrm{M}$ & SD & M & SD & & & & & & & & & & & & \\
\hline & 3.942 & .74 & 3.659 & .69 & & & & & & & & & & & & \\
\hline \multirow[b]{3}{*}{ Ability } & Low & & High & & & & & & & & & & & & & \\
\hline & $M$ & $S D$ & $M$ & $S D$ & & & & & & & & & & & & \\
\hline & 4.143 & .73 & 3.457 & .69 & & & & & & & & & & & & \\
\hline \multirow[b]{3}{*}{ Effort } & Low & & High & & & & & & & & & & & & & \\
\hline & $M$ & $S D$ & $M$ & $S D$ & & & & & & & & & & & & \\
\hline & 4.192 & .78 & 3.409 & .70 & & & & & & & & & & & & \\
\hline \multirow[b]{3}{*}{ LD*Effort } & LD LE & & LD HE & & NLD LE & & NLD HE & & & & & & & & & \\
\hline & M & SD & M & SD & M & SD & M & SD & & & & & & & & \\
\hline & 4.177 & .98 & 3.707 & .80 & 4.207 & .90 & 3.110 & .88 & & & & & & & & \\
\hline \multirow{2}{*}{ LV ETTOT } & LD & & LD & & LD & & LD & & NLD & & NLD & & NLD & & NLD & \\
\hline & $\mathrm{M}$ & SD & M & SD & $\mathrm{M}$ & SD & M & SD & $\mathrm{M}$ & SD & M & SD & $\mathrm{M}$ & SD & $\mathrm{M}$ & SD \\
\hline LD*Ability*Effort & 4.354 & 1.08 & 4.171 & .97 & 4.000 & 1.22 & 3.244 & .97 & 4.634 & 1.05 & 3.413 & .99 & 3.780 & 1.02 & 2.805 & 1.20 \\
\hline
\end{tabular}

A significant (small-medium) main effect for SLD status, $F(1,205)=32.258, \mathrm{p}<.001, \eta_{\mathrm{p}}{ }^{2}=$ .137, was found for pre-service teachers' expectations of a student's future failure (see Tables 7 and 8). The $\eta_{\mathrm{p}}{ }^{2}$ and mean score differences between expectations of future failure for students with $(M=3.942)$ and without SLD $(M=3.659)$ can be noted. A significant main 
effect for ability, $\mathrm{F}(1,205)=203.425, \mathrm{p}<.001, \eta_{\mathrm{p}}{ }^{2}=.499$ (large effect size), was found for pre-service teachers' expectations of a student's future failure. The differences in $\eta_{\mathrm{p}}{ }^{2}$ and mean scores between the expectations of future failure for high ability $(M=3.457)$ and low ability students $(M=4.143$ demonstrates this. A large significant main effect for effort, $\mathrm{F}(1$, 205) $=185.245, \mathrm{p}<.001, \eta_{\mathrm{p}}{ }^{2}=.476$, was found for pre-service teachers' expectations of a student's future failure. This is seen in the $\eta_{\mathrm{p}}{ }^{2}$ and mean expectation scores given to the students who expend low effort $(M=4.192)$ and high effort $(M=3.409)$ respectively.

Table 8

Teachers’ Significant Feedback Main Effects

\begin{tabular}{llll}
\hline Effect & $\mathrm{F}$ & $\eta^{2}$ & $\mathrm{p}$ \\
\hline LD Status & 32.258 & .137 & .000 \\
Ability & 203.425 & .499 & .000 \\
Effort & 185.245 & .476 & .000 \\
LD $^{\mathrm{x}}$ Effort & 41.556 & .169 & .000 \\
LD*Ability*Effort & 21.570 & .096 & .000
\end{tabular}

The responses demonstrated a two-way interaction between a student's SLD status and effort with respect to their expectation of future failure for the student, $F(1,205)=41.556, p<.001$, $\eta_{\mathrm{p}}{ }^{2}=.169$ (small-medium effect size). Finally, a small significant three-way interaction effect existed among SLD, ability, and effort in regards to pre-service teachers' expectations of future failure $\mathrm{F}(1,205)=21.570, \mathrm{p}<.01, \eta_{\mathrm{p}}{ }^{2}=.096$.

\section{Discussion}

British pre-service teachers demonstrated attributional styles towards hypothetical boys with SLD that may not be conducive to positive outcomes for those students in inclusive classrooms. Our pre-service teachers felt more sympathy towards, and held lower expectations for the educational success of, the boys who were of low ability, an attribution 
that has been associated with poorer outcomes for students with SLD (Author et al., 2010; Author et al., 2011; Clark, 1997; Georgiou, et al., 2002). Concomitantly, the pre-service teachers recorded more positive feedback, lower levels of frustration, higher levels of sympathy, and lower expectations of future failure when the students expended high levels of effort.

The results also showed that the participants' levels of sympathy varied according to whether the students had SLD or not, although it was consistently greater for the students with SLD in all scenarios. A comparison of the students' ability levels, for example, showed a larger gap between the levels of sympathy elicited for those with and without SLD when the student had high ability; the gap was smaller in the levels of sympathy when the students had low ability. A similar pattern was evident in relation to effort, whereby there was a greater difference for feedback, favoring the students with SLD, when low effort was expended compared to the high effort scenario. In other words, when the students had SLD, the feedback was more positive than that given for students who did not have SLD and expended similar low levels of effort. Additionally, the pre-service teachers reported higher levels of frustration towards the students who did not have SLD compared to those with SLD, and the difference was much greater when low effort was expended. Sympathy levels for all students were higher when greater effort was expended but, again, the gap between students with SLD and those without SLD was greater when low effort was expended. When students expended low effort, the pre-service teachers demonstrated similar expectations for future failure, irrespective of the SLD status of the student. However, when high effort was expended, the level of sympathy was higher for the students with SLD than it was for those without SLD. 
It is clear, then, that the British pre-service teachers in the current study varied in their attributional responses according to the SLD status of the students who had failed a test. On the attributional dimension of controllability described by Weiner $(1979,1986)$, the preservice teachers recorded more positive feedback, greater sympathy and lower frustration for the failure of students with SLD when the cause was more within the students' control. A similar pattern was found with respect to the pre-service teachers' expectations of future failure, which were greater for students with SLD when the cause was controllable. This accords with previous research that demonstrated similar patterns of attributions for students with SLD (Author et al., 2010; Author et al., 2011; Brady \& Woolfson, 2008; Clark \& Artiles, 2000).

The generally more positive attitudes that pre-service teachers hold towards students with disabilities (Alghazo \& Naggar Gaad, 2004; Brady \& Woolfson, 2008) is reflected in their desire to be kind, which Weiner (1986) described as a normative response to those students who may face additional challenges in their education. Our sample reported the greatest frustration, least sympathy, and most negative feedback for the high ability, low effort students without SLD. It is likely that they did so because they perceived that these boys' failures were within their personal control and therefore, held them responsible. By contrast, the pre-service teachers recorded the least frustration, greatest sympathy, and most positive feedback for the low ability, high effort students with and without SLD. These affective responses were most likely generated because the pre-service teachers believed that the cause was outside the students' control.

Results in the present study pose a paradox for teacher educators. On the one hand, we want our future teachers to hold positive attitudes towards all their students. However, we need to 
ensure that they are also aware of the impact of their differential affective responses on the students' beliefs about themselves, particularly as the literature has shown that these positive affective responses are not necessarily conducive to the motivation, resilience and ongoing academic outcomes of students with SLD (Author et al., 2010; Author et al., 2011; Clark, 1997; Georgiou, et al., 2002). The importance of this distinction provides a compelling case for closer attention to the training provided to pre-service teachers who will be responsible for ensuring the successful inclusion of students with SLD in their mainstream classrooms. In particular, training needs to draw pre-service teachers' attention to the potential impact of their attitudes on their subsequent pedagogical choices for students with SLD.

In line with other research (Malinen, et al., 2013), our research confirms the need to ensure that pre-service teacher-training courses do not simply pay lip-service to student diversity but provide nuanced learning among pre-service teachers regarding inclusive practices. Many pre-service teacher training courses include a generic unit on inclusive education that may focus on the various categories of disabilities. The content of such courses, in the light of our research, however, needs to include a focus on teachers' attitudes (Carroll, et al., 2003), drawing attention to the potential impact of their attributions on students with SLD. This is particularly pertinent given other research that indicated that it is the content and pedagogy of the training that is most critical for the formation of positive attitudes among pre-service teachers (Sharma, et al., 2008). Activities aimed at developing positive teacher self-efficacy (Woolfson \& Brady, 2009) would help pre-service teachers examine the attributions they make for students' performance in the classroom. These activities may include scheduled and planned interactions with students with SLD during their professional practice in schools (Brady \& Woolfson, 2008). In summary, the British pre-service teachers in our research seem motivated to be effective teachers in their inclusive classrooms but require the training that 
will give them the attitudes, knowledge and skills to fulfil their responsibility. Thus, as the Government's interventions so far have had limited success, we would recommend that the new Teachers’ Standards (DfE, 2012) incorporate a mandatory minimum level of SLD training (Rose, date?).

Teacher attitudes are critical to the success of the inclusion agenda throughout the world. Our research has demonstrated that, at least for this sample, the attributions they make differ according to a student's SLD status and characteristics. We have argued that teacher training programs need to shift teachers' attitudes away from a deficit view of learners to one where teachers believe that they can make a difference for such students. This is a particular challenge for a diverse country such as the United Kingdom where multiple jurisdictions and LEAs determine educational policies and practices. Hence, there is a compelling need for a national approach that is driven by research in the British context (Lyon, 2005). For SLD, this would include a shared understanding of definitions and best practice approaches to curriculum differentiation (Philpott \& Cahill, 2008).

\section{Limitations}

As well as the limitations discussed earlier, other limitations include the focus on attitudes and the gendered vignettes. The research examined attitudes of pre-service teachers, which is only one component affecting the teacher's potential classroom behaviors. Therefore, the need remains for future research to investigate how teachers' attributions are enacted in the classroom and how these may influence student outcomes (Gibbs, 2007). Finally, findings need to be considered with caution as only boys were used in the study and therefore future studies should investigate responses to boys and girls and consider whether 
any gender differences apply. Furthermore, future studies could consider alternative data collection methods such as mixed or qualitative methods.

\section{Conclusion}

While research on pre-service teachers has posited that they generally hold more positive attitudes toward students with disabilities than their in-service counterparts (Alghazo \& Naggar Gaad, 2004; Garmon, 2004; Glaubman \& Lifshitz, 2001), our study provides some evidence that this may not be the case. Rather, our research has demonstrated that pre-service teachers’ attributional styles are potentially negative for students with disabilities. Our participants differentiated between students with and without SLD, irrespective of those students’ abilities and effort. By showing more positive feedback and greater sympathy for the failures of students with SLD, the pre-service teachers are potentially communicating the belief that the students with SLD are not capable of high achievement. This finding adds to the work of Clark (1997) whereby teachers' attributions were associated with the outcomes of students with disabilities. It also complements the research of Brady and Woolfson (2008) who concluded that in-service teachers with higher levels of efficacy showed more positive attributional styles towards students with LD. Lower levels of sympathy for such students' failures, for example, illustrated their beliefs that the students' performance could improve with their intervention.

Despite the progress that has been made on inclusion, there are still issues with the attitudes, knowledge and skills of teachers regarding students with SLD. Most universities have introduced compulsory training in inclusive education to redress this shortcoming. Nevertheless, our research shows that pre-service teachers, despite receiving tuition in inclusive education, attribute failures in students with SLD to causes that may not be 
conducive to their motivation or future attainments. For such students to enjoy similar educational opportunities to their peers, teachers must be equipped to meet the students' needs. Hence, we must address the development of positive attitudes on the part of teachers towards the full range of diverse needs they will encounter.

\section{References}

Abbott, L. (2006). Northern Ireland head teachers’ perceptions of inclusion. International Journal of Inclusive Education, 10, 627-643.

Alghazo, E.M., \& Naggar Gaad, E.E. (2004). General education teachers in the United Arab Emirates and their acceptance of the inclusion of students with disabilities. British Journal of Special Education, 31, 94-99.

Author et al., 2010

Author et al., 2011

Avramidis, E., Bayliss, P., \& Burden, R. (2000). Student teachers’ attitudes towards the inclusion of children with special educational needs in the ordinary school. Teaching and Teacher Education, 16, 277-293.

Avramidis, E., \& Kalyva, E. (2007). The influence of teaching experience and professional development on Greek teachers’ attitudes towards inclusion. European Journal of Special Needs Education, 22, 367-389.

Avramidis, E., \& Norwich, B. (2002). Teachers’ attitudes towards integration/inclusion: a review of the literature. European Journal of Special Needs Education, 17, 129-147.

Batsiou, S., Bebetsos, E., Panteli, P., \& Antoniou, P. (2008). Attitudes and intention of Greek and Cypriot primary education teachers towards teaching pupils with special educational needs in mainstream schools. International Journal of Inclusive Education, 12, 201-219. 
Berry, R.W. (2008). Novice teachers' conceptions of fairness in inclusion classrooms. Teaching and Teacher Education, 24(5), 1149-1159.

Brady, K., \& Woolfson, L. (2008). What teacher factors influence their attributions for children’s difficulties in learning? British Journal of Educational Psychology, 78, 527-544.

Carroll, A., Forlin, C., \& Jobling, A. (2003). The impact of teacher training in special education on the attitudes of Australian preservice general educators towards people with disabilities. Teacher Education Quarterly, 30 (3), 65-79.

Chan, D. (2009). So why ask me? Are self report data really that bad? In Lance, C. E. \& Vandenberg, R. J. (Eds.), Statistical and methodological myths and urban legends: Doctrine, verity and fable in the organizational and social sciences (pp. 309-335). New York: Routledge.

Clark, M. (1997). Teacher response to Learning Disability: a test of attributional principles. Journal of Learning Disabilities, 30(1), 69-79.

Clark, M., \& Artiles, A. (2000). A cross-national study of teachers' attributional patterns. The Journal of Special Education, 34(2), 77-89.

Clunies-Ross, P., Little, E., \& Kienhuis, M. (2008). Self-reported and actual use of proactive and reactive classroom management strategies and their relationship with teacher stress and student behaviour. Educational Psychology, 28, 693-710.

Cook, B.G. (2001). A comparison of teachers' attitudes toward their included students with mild and severe disabilities. The Journal of Special Education, 34, 203-213.

de Boer, A., Pijl, S.P., \& Minnaert, A. (2011). Regular primary schoolteachers’ attitudes towards inclusive education: a review of the literature. International Journal of Inclusive Education, 15(3), 331-353.

DFE (2012). Teachers’standards. Department for Education. 
DFES. (2001). Special Educational Needs: Code of Practice. Department for Education and Skills.

Engelbrecht, P. (2006). The implementation of inclusive education in South Africa after ten years of democracy. European Journal of Psychology of Education, 21(3), 253-264.

Forlin, C. (2010). Teacher education reform for enhancing teachers' preparedness for inclusion. International Journal of Inclusive Education, 14 (7), 649-653.

Gans, A., Kenny, M., \& Ghany, D. (2003). Comparing the self-concept of students with and without learning disabilities. Journal of Learning Disabilities, 36, 287-295.

Garmon, M. (2004). Changing preservice teachers’ attitudes/beliefs about diversity: What are the critical factors? Journal of Teacher Education, 55(3), 201-213.

General Teaching Council for England. (2009). Annual digest of statistics 2008-2009:

Profiles of registered teachers in England (Accessed: $9^{\text {th }}$ February 2013). http://www.gtce.org.uk/ documents/publicationpdfs/ annual_digest_psd090809.pdf.

Georgiou, S., Christou, C., Stavrinides, P., \& Panoura, G. (2002). Teacher attributions of student failure and teacher behavior toward the failing student. Psychology in the Schools, 39(5), 583-595.

Gibbs, S. (2007). Teachers' perceptions of efficacy: beliefs that support inclusion or segregation. Educational and Child Psychology, 24(3), 47-53.

Glaubman, R., \& Lifshitz, H. (2001). Ultra-orthodox Jewish teachers' self-efficacy and willingness for inclusion of pupils with special needs. European Journal of Special Needs Education, 16, 207-223.

Heiman, T. (2006). Social support networks, stress, sense of coherence and academic success of university students with learning disabilities. Social Psychology of Education, 9, 461-478. 
Jacobson, B., Lowery, B., \& DuCette, J. (1986). Attributions of learning disabled children. Journal of Educational Psychology, 78(1), 59-64.

Jordan, A., Glenn, C., \& McGhie-Richmond, D. (2010). The Supporting Effective Teaching (SET) project: the relationship of inclusive teaching practices to teachers' beliefs about disability and ability, and about their roles as teachers. Teaching and Teacher Education, 26, 259-266.

Kozleski, E.B., \& Waitoller, F.R. (2010). Teacher learning for inclusive education: Understanding teaching as a cultural and political practice. International Journal for Inclkusive Education, 14 (7), 655-666.

Lerner, J., \& Johns, B. (2009). Learning disabilities and related mild disabilities (11 ${ }^{\text {th }}$ edn.). New York: Houghton/Mifflin.

Leyser, Y., Zeiger, T., \& Romi, S. (2011). Changes in self-efficacy of prospective special and general education teachers: implications for inclusive education. International Journal of Disability, development \& Education, 58(3), 241-255.

Lifshitz, H., Glaubman, R., \& Issawi, R. (2004). Attitudes towards inclusion: the case of Israeli and Palestinian regular and special education teachers. European Journal of Special Needs Education, 19, 171-190.

Lindsay, G. (2007). Educational psychology and the effectiveness of inclusive education/mainstreaming. British Journal of Educational Psychology, 77, 1-24.

Loreman, T., Forlin, C., \& Sharma, U. (2007). An international comparison of pre-service teacher attitudes towards inclusive education. Disability Studies Quarterly, 27(4). Retrieved July 20, 2012, from www.dsq-sds.org.

Lyon, G.R. (2005). Why scientific research must guide educational policy and instructional practices in learning disabilities. Learning Disability Quarterly, 28(2), 140-143. 
Malinen, O., Savolainen, H., Engelbrecht, P., Xu, J., Nel, M., Nel, N., \& Tlale, D. (2013). Exploring teacher self-efficacy for inclusive practices in three diverse countries. Teaching and Teacher Education, 33, 34-44.

Malinen, O., Savolainen, H., \& Xu, J. (2012). Beijing in-service teachers’ self-efficacy and attitudes towards inclusive education. Teaching and Teacher Education, 28(4), 526534.

Marshall, J., Ralph, S., \& Palmer, S. (2002). 'I wasn’t trained to work with them’: mainstream teachers’ attitudes to children with speech and language difficulties. International Journal of Inclusive Education, 6, 199-215.

Mittler, P. (1992). Preparing all initial teacher training students to teach children with special educational needs: a case study from England. European Journal of Special Needs Education, 7 (1), 1-9.

Nunez, J., Gonzalez-Pienda, J., Gonzalez-Pumariega, S., Roces, C., Alvarez, L., Gonzalez, P., Cabanach, R., Valle, A., \& Rodriguez, S. (2005). Subgroups of attributional profiles in students with learning difficulties and their relation to self-concept and academic goals. Learning Disabilities Research and Practice, 20(2), 86-97.

Parasuram, K. (2006). Variables that affect teachers’ attitudes towards disability and inclusive education in Mumbai, India. Disability and Society, 21, 231-242.

Philpott, D.F., \& Cahill, M. (2008). A Pan-Canadian perspective on the professional knowledge base of learning disabilities. International Journal of Disability, Community and Rehabilitation, 7(2). Retrieved February 11, 2013, from http://www.ijdcr.ca/VOL07_02_CAN/index.shtml.

Reyna, C., \& Weiner, B. (2001). Justice and utility in the classroom: an attributional analysis of the goals of teachers' punishment and intervention strategies. Journal of Educational Psychology, 93(2), 309-319. 
Richardson, J. (2011). Eta squared and partial Eta squared as measures of effect size in educational research. Educational Research Review, 6(2), 135-147.

Ring, E. (2005). Barriers to inclusion: a case study of a pupil with severe learning difficulties in Ireland. European Journal of Special Needs Education, 20(1), 41-56.

Romi, S., \& Leyser, Y. (2006). Exploring inclusion preservice training needs: a study of variables associated with attitudes and self-efficacy beliefs. European Journal of Special Needs Education, 21(1), 85-105.

Rose, J. (2009). The Rose Review: Identifying and teaching children and young people with dyslexia and literacy difficulties. Nottingham, Department for Children, Schools, and Families Publications.

Ross, J., \& Bruce, C. (2007). Professional development effects on teacher efficacy: results of randomized field trial. Journal of Educational Research, 101(1), 50-60.

Schunk, D., Pintrich, P., \& Meece, J. (2008). Motivation in education: Theory, research, and applications. Sydney: Pearson.

Sharma, U., Ee, J., \& Desai, I. (2003). A comparison of Australian and Singaporean preservice teachers’ attitudes and concerns about inclusive education. Teaching and Learning, 24 (2), 207-217.

Sharma, U., Forlin, C., \& Loreman, T. (2008). Impact of training on pre-service teachers' attitudes and concerns about inclusive education and sentiments about persons with disabilities. Disability \& Society, 23(7), 773-785.

Stone, C., \& May, A. (2002). The accuracy of academic self evaluations in adolescents with learning disabilities. Journal of Learning Disabilities, 35, 370-383.

Stronge, J., Ward, T., Grant, L. (2011). What makes good teachers good? A cross-case analysis of the connection between teacher effectiveness and student achievement. Journal of teacher education, 62(4), 339-355. 
UNESCO (1990). World declaration on education for all and framework for action to meet basic learning needs. Paris, France: UNESCO.

UNESCO (1994). Salamanca statement and framework for action for special needs education. Paris, France: UNESCO.

UNESCO (2007). Policy guidelines on inclusion in education. Paris, France: UNESCO.

Waheeda, T., \& Grainger, J. (2002). Self-concept, attributional style and self-efficacy beliefs of students with learning disabilities with and without attention deficit hyperactivity disorder. Learning Disability Quarterly, 25(2), 141-151.

Walton, E. (2011). Getting inclusion right in South Africa. Intervention in School and Clinic, 46(4), 240-245.

Weiner, B. (1979). A theory of motivation for some classroom experiences. Journal of Educational Psychology, 71(1), 3-25.

Weiner, B. (1985). An attributional theory of achievement motivation and emotion. Psychological Review, 92, 548-573.

Weiner, B. (1986). An attributional theory of motivation and emotion. New York: SpringerVerlag.

Weiner, B., Russell, D., \& Lerman, D. (1978). Affective consequences of causal ascriptions. In J. H. Harvey, W. J. Ickes \& R. F. Kidd (Eds.), New directions for attribution research ( $2^{\text {nd }}$ Ed.) (pp. 59-90). Hillsdale, NJ: Erlbaum.

Woolfolk Hoy, A., \& Spero, R. (2005). Changes in teacher efficacy during the early years of teaching: a comparison of four measures. Teaching and Teacher Education, 21, 343356.

Woolfson, L.M., \& Brady, K. (2009). An investigation of factors impacting on mainstream teachers' beliefs about teaching students with learning difficulties. Educational 
Psychology: An International Journal of Experimental Educational Psychology, 29(2), 221-238. 